\title{
APLICAÇÃO DA ENGENHARIA DE MÉTODOS PARA FABRICAÇÃO DE UM JOGO CORPORATIVO
}

Gabriel Mendes de Souza, (UFCG), gabrielmendes384@gmail.com Rian Moura Café Amorim, (UFCG), rian_moura@ hotmail.com Natália Albuquerque dos Santos, (UFCG), natalia.dealbuquerque@ hotmail.com Fernandes José de Melo Júnior, (UFCG), fernandes_jmj@ @otmail.com

\section{Resumo}

Procurar melhorias em seu processo produtivo com o intuito de aumentar a eficiência, bem como maximizar a capacidade produtiva são uns dos principais objetivos da engenharia de métodos. Diante disso, é válido salientar que os jogos corporativos podem ser usados com a finalidade de estimular o trabalho em grupo por meio de dinâmicas colaborativas que incentivam a convicção entre participantes da mesma equipe com o objetivo de haver mais certeza no momento de exercerem o trabalho em conjunto. $\mathrm{O}$ presente trabalho tem como objetivo a aplicação da engenharia de métodos em um jogo corporativo ao fazer a cronometragem de cada operação e, consequentemente, fazer a cronoanálise, estabelecendo o melhor tempo, método e movimento. Após a realização do estudo, foi-se possível observar que a utilização do produto é de grande aplicabilidade nas instituições de ensino. Destarte, algumas melhorias propostas no trabalho são de fácil aplicabilidade como as questões de melhoramento de processos ao ter mais agilidade na execução de uma determinada tarefa.

Palavras-chave: Engenharia de métodos. Jogo corporativo. Capacidade produtiva. Processo produtivo.

\section{Introdução}

Ir atrás de evoluções em seu processo produtivo com interesse de aumentar sua eficiência, bem como desenvolver sua capacidade produtiva são uns dos propósitos da engenharia de métodos. Diminuir o lead time, descobrir a forma mais conveniente de desempenhar procedimentos operacionais, sugerir medidas que amplifique a capacidade produtiva da organização e diminuir os seus gastos operacionais, dentre outros benefícios, conseguem ser obtidos com a utilização da engenharia de métodos. 
Fazer com que os procedimentos diários da empresa se tornem tarefas agradáveis, acabou se tornando uma prioridade para os responsáveis, visto que é um método interessante para encorajar os trabalhadores e fazer com que o cotidiano da organização seja mais ameno e tranquilo, além de encorajar a disputa saudável e mais foco por parte dos colaboradores. Por essa razão, os jogos corporativos (business games) têm se revelado uma excelente opção para escapar da mesmice das rotinas de trabalho e desenvolver ainda mais as qualidades e competências.

Os Jogos Corporativos podem ser aplicados a fim de incentivar o trabalho em equipe mediante procedimentos colaborativos que ocasionam a firmeza entre integrantes da mesma equipe, para que tenham mais segurança na hora de realizarem a tarefa juntos. Nesse contexto, estipular metas e prazos como intuito fundamental dos jogos é capaz de ajudar seus colaboradores a idealizarem um comportamento de cumprimento de prazos, estabelecendo com que as entregas se tornem mais efetivas e pontuais (REGINA, 2018).

O presente trabalho tem como objetivo a aplicação da engenharia de métodos em um jogo corporativo a realizar a cronometragem de cada operação e, consequentemente, fazer a cronoanálise com o intuito de conseguir armazenar a maior quantidade de bolas de gude no reservatório no menor tempo possível.

\section{Desenvolvimento}

\subsection{Estudo de movimentos e tempos}

De acordo com Barnes (1977), o estudo de movimento e tempos pode ser entendido como um sistema sistemático de trabalho que possa atingir as seguintes metas: desenvolvimento em relação ao sistema e método preferido, o que possui custo em quantidades menores; haver a padronização desse sistema e método; determinar o tempo consumido por cada operador qualificado e treinado, executando uma tarefa específica num ritmo normal com a finalidade de orientar o trabalhador no método preferido escolhido por este.

O estudo de movimento e métodos pode ser composto por quatro principais partes, porém as mais estudadas são apenas as duas principais: o estudo de movimentos ou projeto de métodos, a qual é responsável por encontrar o melhor método com a finalidade da tarefa ser executada e o estudo de tempo e medidas de trabalho que é responsável pela determinação do tempo padrão à elaboração de uma atividade específica (BARNES,1977). 
O estudo da engenharia de métodos é iniciado em 1881 numa usina chamada de Midvalle Stell Company com Frederick Taylor sendo o introdutor. Atualmente, tal técnica é utilizada ao planejamento e padronização em relação à execução de quaisquer trabalhos, submetendo uma análise de maneira detalhada no que tange a cada operação de uma determinada atividade ,com o intuito de que elementos, que não sejam imprescindíveis, sejam eliminados durante a operação dessa certa atividade para determinar, consequentemente, o método mais eficiente de execução da tarefa (PEINADO, 2007).

\subsection{Cronoanálise}

O tempo padrão é o tempo que se determina para um determinado operário realizar as atividades dele em quantidades específicas a seguir um método já estabelecido em ritmo normal, sem perdas de tempo, estando sujeito a tanto fadigas quanto demoras. Ele é definido na cronometragem e não existe relevância quando estar apenas só. Nesse sentido, a cronometragem é considerada uma ferramenta à cronoanálise e, dessa forma, o responsável por executar a cronoanálise recebe nome de cronoanalista (ANIS,2010).

A cronoanálise pode ser usada com a finalidade de cronometrar e verificar o tempo gasto por um operador em relação à execução de uma determinada atividade no fluxo de produção, o que permite ao trabalhador um tempo de tolerância referente às atividades fisiológicas, quebras de máquinas, entre outros. Além do mais, é válido salientar que o profissional que executa a cronoanálise é chamado de cronoanalista sendo o responsável por orientar e otimizar a sequência operacional a verificar o procedimento adequado a ser executado em certas tarefas (OLIVEIRA,2009).

\subsection{Gráfico das duas mãos}

“O diagrama de processo de duas mãos, também conhecido como diagrama SIMO (movimentos simultâneos), é uma técnica utilizada para estudos de fluxos de produção que envolve montagem ou desmontagem de componentes." (PEINADO, 2007).

Conforme Peinado (2007), para que haja a elaboração do diagrama de duas mãos, é necessário: apresentar o produto final e os componentes dele; ter a elaboração do layout dos componentes que devem ser montados de forma interna em relação à área normal de montagem; apresentar a 
sequência dos movimentos na qual deve ser efetuada a montagem; registrar o método usado como padrão de referência na forma de documento; padronizar o processo e, por fim, executar a sequência dos movimentos no menor tempo possível, otimizando a execução do trabalho e reduzindo consequentemente os tempos normais com o intuito de que a produtividade seja aumentada.

\subsection{Jogos corporativos}

De acordo com Shimizu (2001), jogos corporativos mais conhecidos como jogos de empresas podem ser definidos como: "um exercício sequencial de decisão estruturado sobre um modelo de simulação empresarial, em que os participantes assumem o papel de gerentes da operação simulada."

Segundo Santos na sociedade contemporânea:

“Os jogos das empresas são abstrações matemáticas simplificadas de uma situação relacionada com o mundo dos negócios. Os participantes dos jogos, individualmente ou em equipes, administram a empresa como um todo ou em parte dela, através de decisões sequenciais. Os jogos das empresas também podem ser definidos como um exercício de tomada de decisões em torno de um modelo de operação de negócios, no qual os participantes assumem o papel de administradores de uma empresa simulada [... podendo] assumir diversos papéis gerenciais, funcionais, especialistas, generalistas etc. Definem objetivos e metas gerais e específicos, estratégias gerais e específicas, analisam os resultados das decisões tomadas." (LACRUZ, v. 11, n. 4, p. 93-109, 2004; apud SANTOS,2003).

Os jogos de empresas têm a mesma estrutura de jogos normais, entretanto voltados à área empresarial com a finalidade de simular características econômicas, sociais e técnicas em relação ao ambiente das organizações. Este método é responsável por simular uma empresa que é um sistema complexo possuindo recursos físicos, processos, pessoas, produtos, clientes, dessa maneira, operando em ambiente que seja competitivo (NEVES,2014).

\section{Metodologia}

A pesquisa teve como finalidade a elaboração de um jogo corporativo aplicando os conhecimentos adquiridos em engenharia de métodos. Ele foi desenvolvido na cidade de SuméPB. Diante de várias pesquisas bibliográficas realizadas em livros, sites e em programas de 
televisão como o de Silvio Santos no SBT, foi decidido como o jogo corporativo seria desenvolvido. Inicialmente, foi feito um protótipo mostrado na figura 1 mediante o programa sketchup. Dessa forma, consequentemente, foi possível analisar o design e funcionalidade do projeto de forma virtual.

Figura 1: Protótipo no sketchup

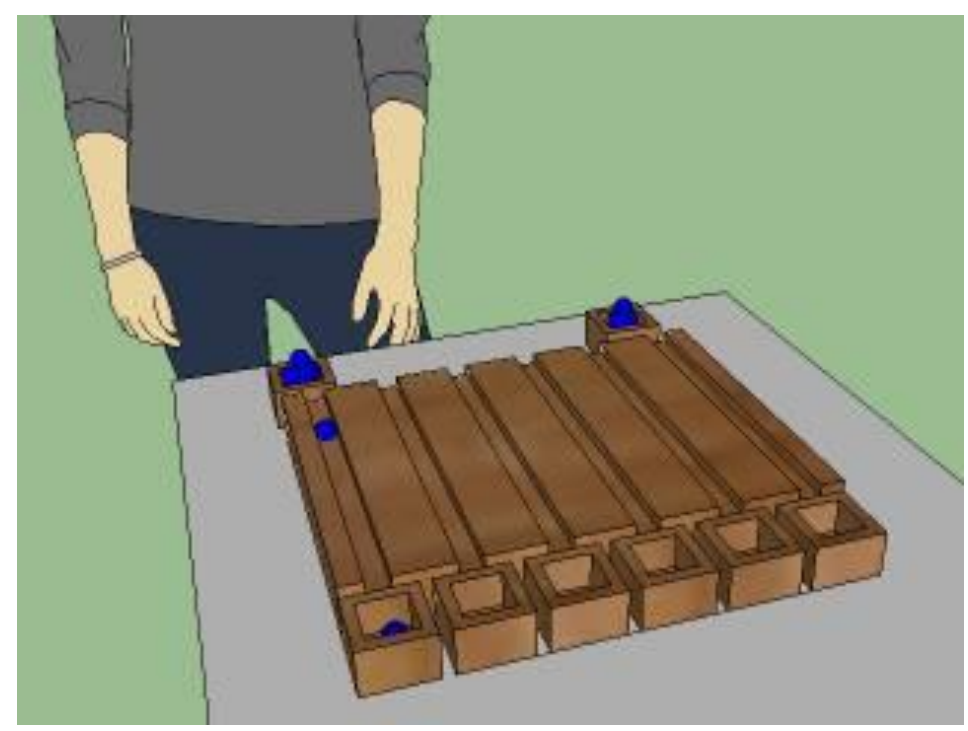

Fonte: Autoria Própria (2019)

Posteriormente, o protótipo foi impresso e levado até uma marcenaria, onde foi desenvolvido por um marceneiro as seis "rampas" como mostrado nas figuras 2 e 3 do projeto com material de madeira. Além disso, foram compradas trinta e seis bolas de gude como exibido na figura 4 e oito caixas de madeira como é visto na figura 5, onde duas caixas têm a finalidade de ser usadas como contêineres e seis caixas utilizadas como depósitos, ambas para as bolas de gude. 
Figura 2: Rampas de madeira na vista superior

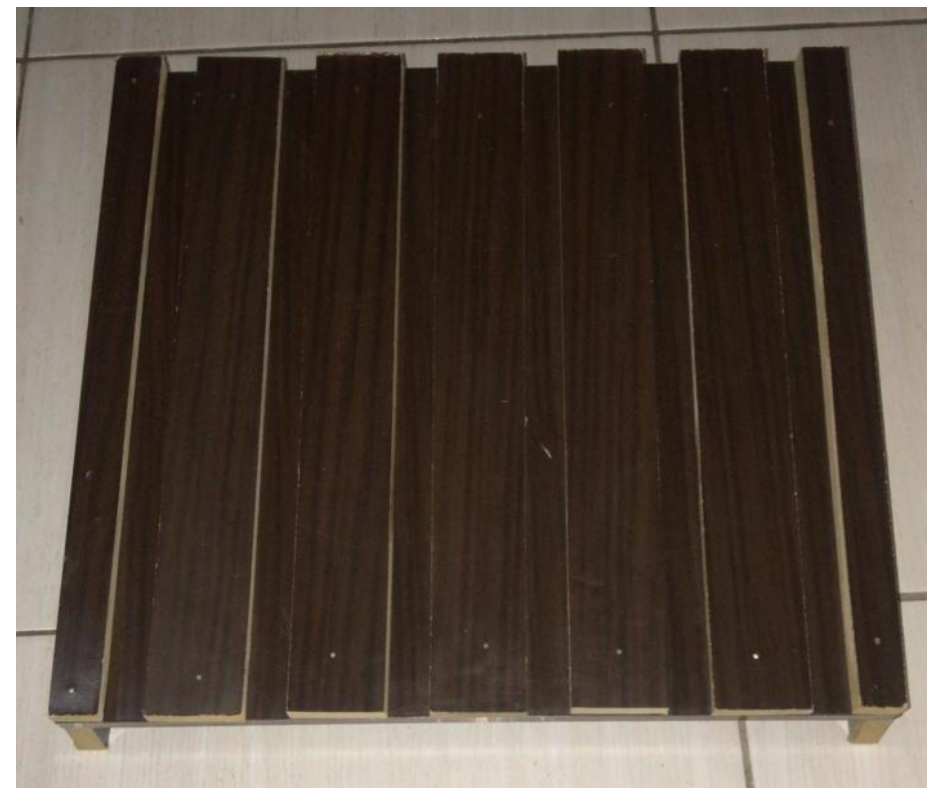

Fonte: Autoria Própria (2019)

Figura 3: Rampas de madeira na vista diagonal

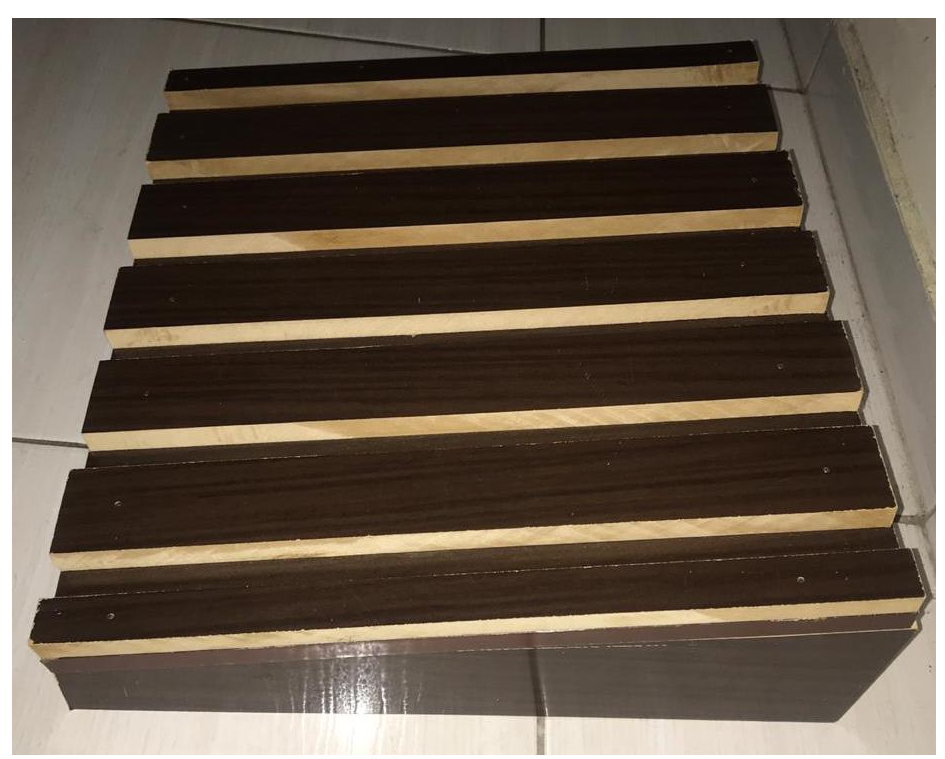

Fonte: Autoria Própria (2019) 
Figura 4: Bolas de gude

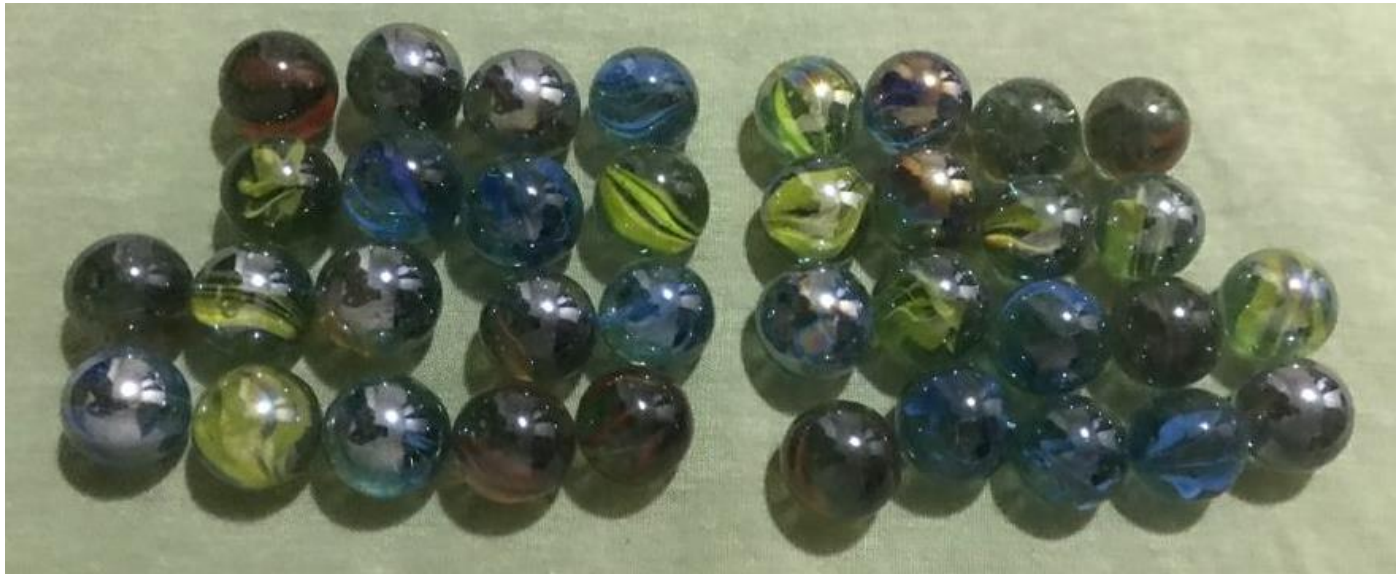

Fonte: Autoria Própria (2019)

Figura 5: Caixas de madeira

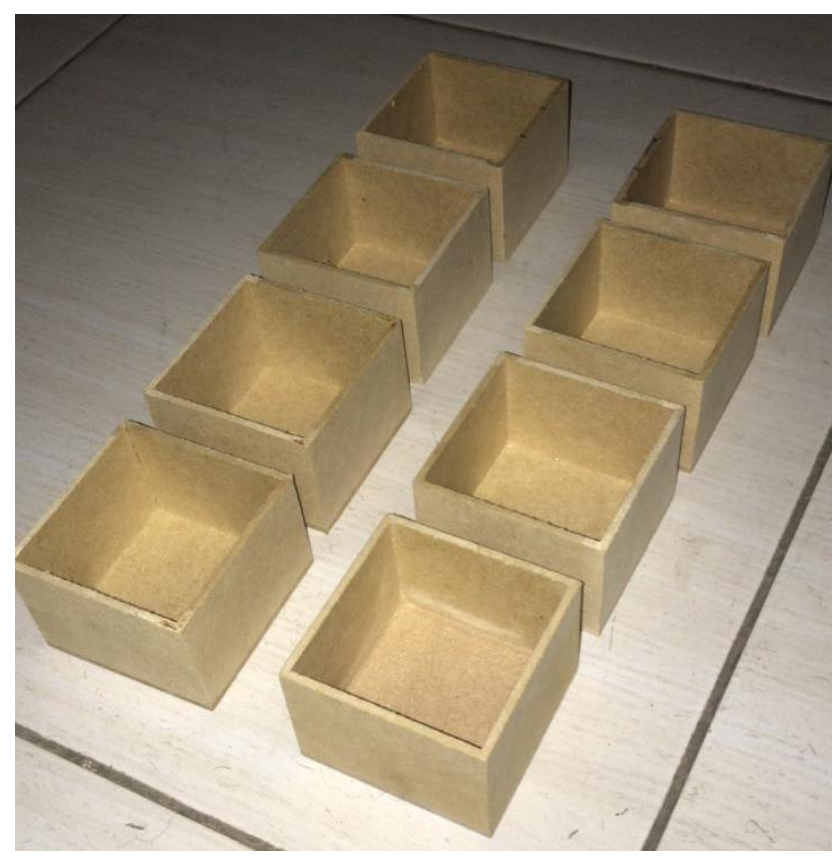

Fonte: Autoria Própria (2019)

Para uma melhor orientação e explicação de como o jogo funciona, é necessário a enumeração das caixas e das rampas por onde descem as bolas de gude aos depósitos, sendo:

- Números 1 e 2 nas duas caixas utilizadas como contêineres;

- Números de 1 a 6 nas seis rampas por onde as bolas de gude descem para os depósitos;

- Número 7 em duas caixas utilizadas como depósitos;

- Número 6 em duas caixas usadas como depósitos; 
- Número 5 em duas caixas usadas como depósitos.

Após esse procedimento completo ser realizado, o jogo foi finalizado e exposto na figura 6.

Figura 6: Jogo finalizado

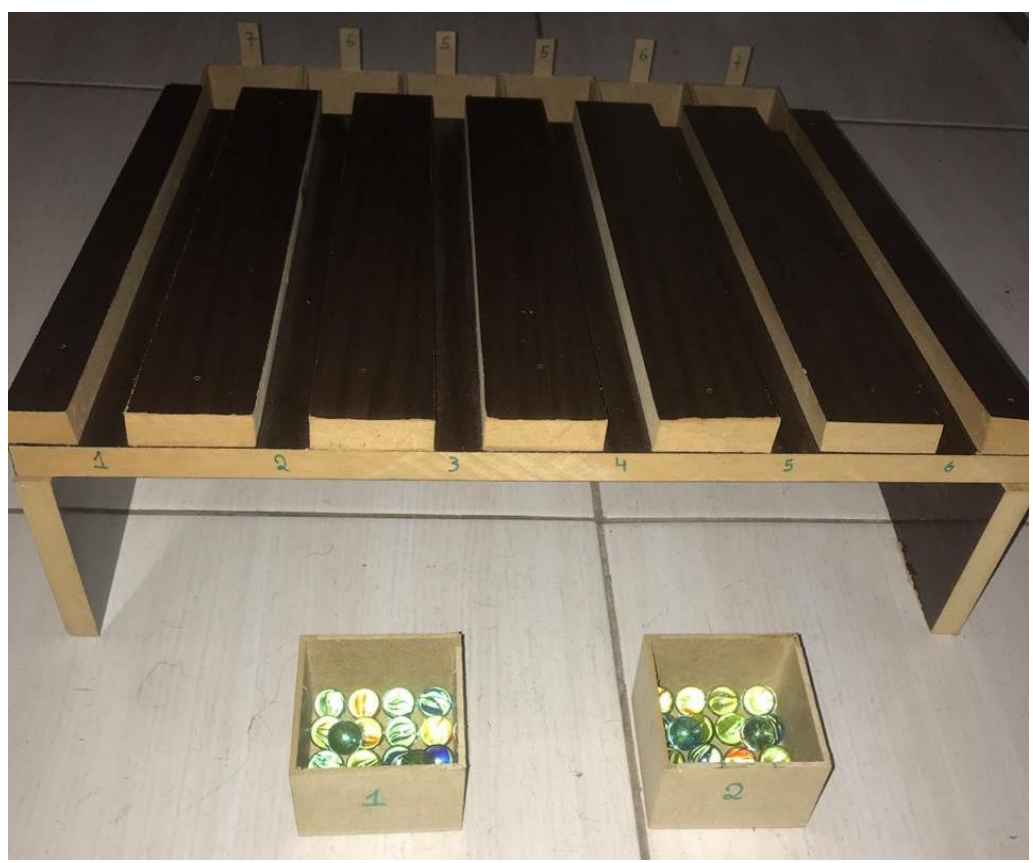

Fonte: Autoria Própria (2019)

Na figura 7, foi ilustrado o fluxograma metodológico, que mostra o passo a passo das etapas que foram seguidas para a conclusão da pesquisa. 
Figura 7: Fluxograma metodológico

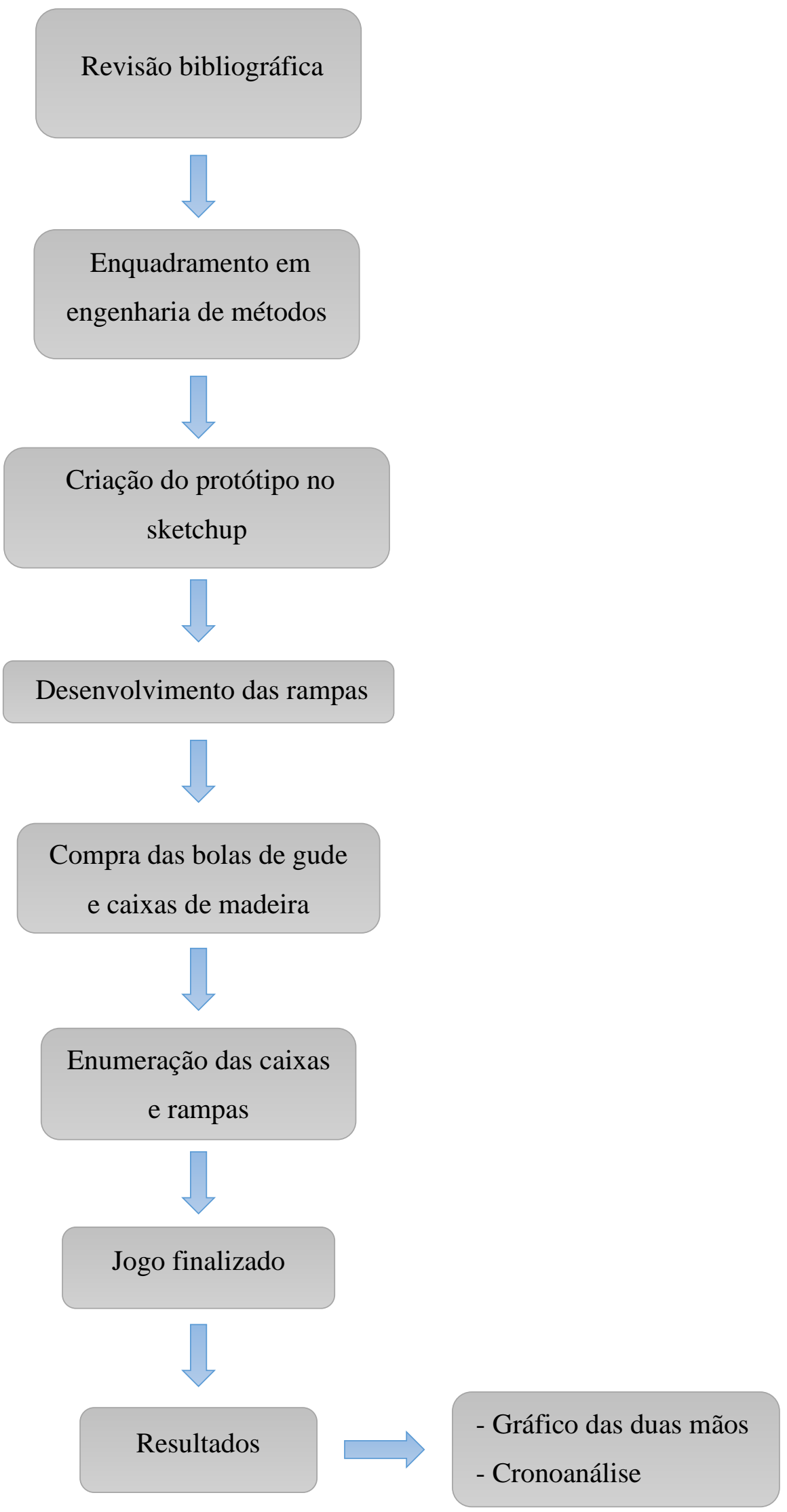

Fonte: Autoria Própria (2019) 


\section{Resultados}

O jogo funciona da seguinte forma: é necessário pegar uma bola de gude que fica armazenada nos contêineres com o objetivo de levá-la até a rampa. Diante disso, a bola de gude se desliza na rampa até o depósito. Sendo assim, a intenção é tentar armazenar todas as bolas de gude nos depósitos de maneira correta no menor tempo possível.

O método do jogo foi escolhido devido a maior agilidade no processo, fazendo com que se torne mais rápido para utilizar todas as bolas de gude possíveis. Diante disso, os depósitos foram enumerados com a quantidade de bolas de gude que são corretas em cada um; as rampas, de 1 a 6 e os contêineres, de 1 a 2 para uma melhor visualização de quem utiliza o jogo, consequentemente, melhorando a produtividade do tempo do jogador.

\subsection{Elaboração do gráfico das duas mãos}

O jogo é dividido em três etapas sequenciais expostas nos três gráficos das duas mãos abaixo:

\section{Gráfico 1: Esse processo se repete por 7 vezes}

Mão esquerda

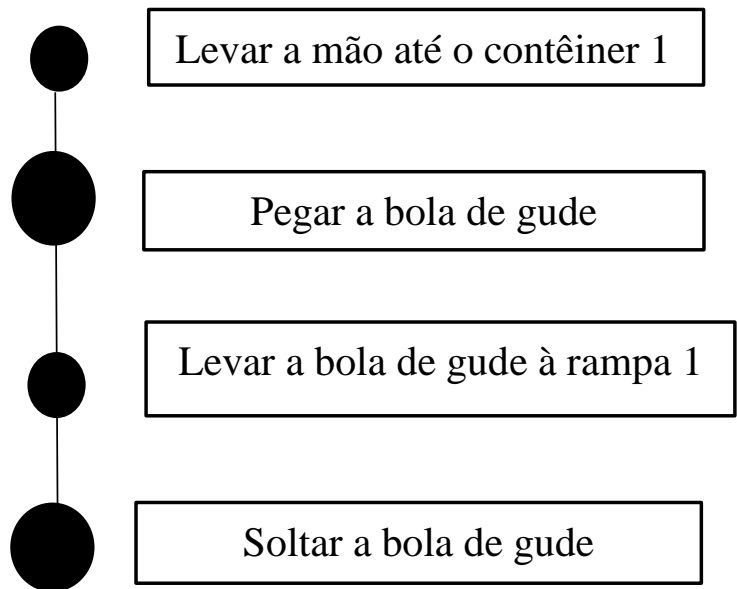

Mão direita

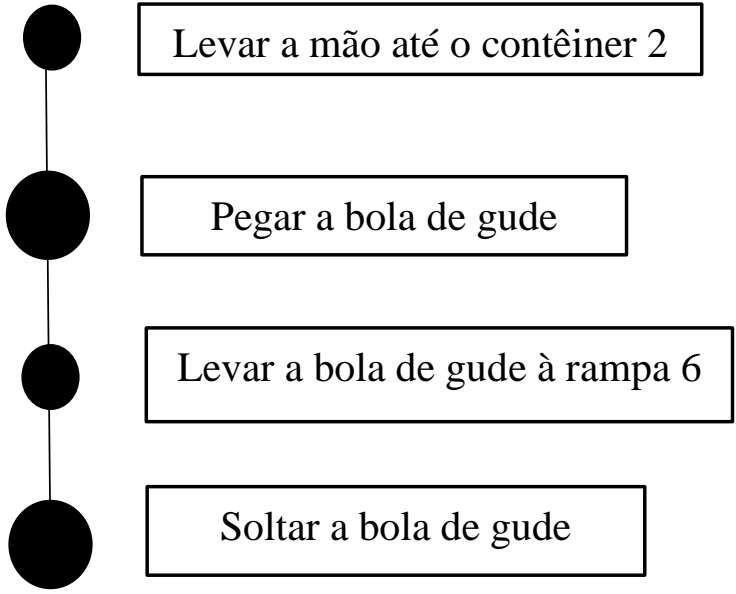

Fonte: Autoria própria (2019) 
Mão esquerda

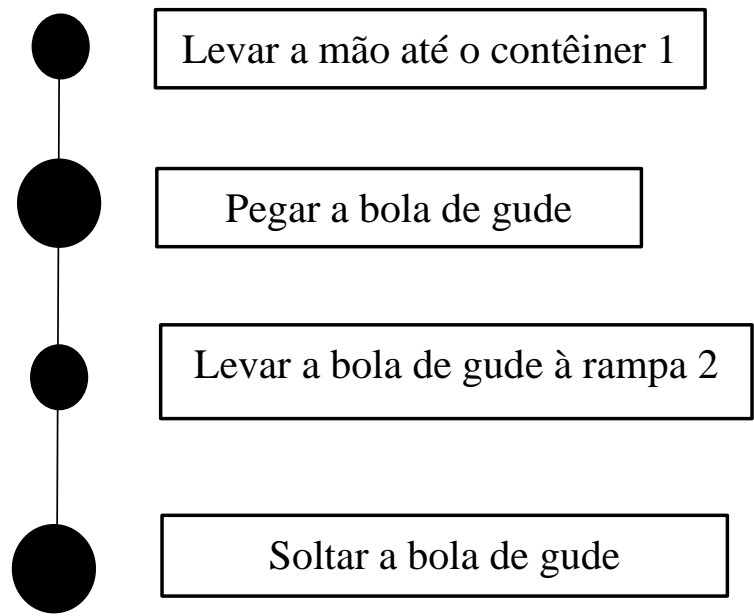

Mão direita

Levar a mão até o contêiner 2

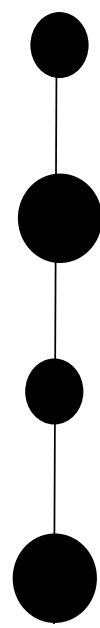

Pegar a bola de gude

Levar a bola de gude à rampa 5

Soltar a bola de gude

Fonte: Autoria própria (2019)

Gráfico 3: Esse processo se repete por 5 vezes

Mão esquerda

Mão direita

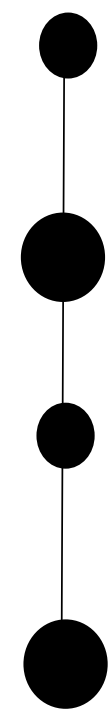

Levar a mão até o contêiner 1

Pegar a bola de gude

Levar a bola de gude à rampa 3

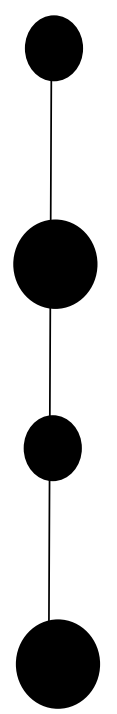

Levar a mão até o contêiner 2

Levar a bola de gude à rampa 4

Soltar a bola de gude

Fonte: Autoria própria (2019)

Pegar a bola de gude

Soltar a bola de gude 


\subsection{Realização da cronoanálise}

A tabela 1 mostra a realização da cronoanálise após o gráfico das duas mãos já produzido.Nela ,é constituido o número de repetições; o tempo normal, aquele cronometrado para cada operação até a última delas ser feita ; o tempo normal padrão que é entendido como o tempo normal sendo multiplicado pelo fator de tolerância e o tempo normal total cronometrado sem interferência.

Tabela 1: Cronoanálise

\begin{tabular}{|c|l|c|c|c|c|}
\hline & \multicolumn{1}{|c|}{ Atividades } & R & TN (s) & TP (s) & TNT (s) \\
\hline 1 & Pegar as peças dos contêineres 1 e 2 & 7 & 4,2 & 4,83 & \\
\hline 2 & Levar as peças até as rampas 1 e 6 & 7 & 4,55 & 5,24 & \\
\hline 3 & Retornar as mãos aos contêineres 1 e 2 & 6 & 3,6 & 4,14 & \\
\hline 4 & Pegar as peças dos contêineres 1 e 2 & 6 & 3,6 & 4,14 & \\
\hline 5 & Levar e soltar as peças nas rampas 2 e 5 & 6 & 3,9 & 4,48 & \\
\hline 6 & Retornar as mãos aos contêineres 1 e 2 & 5 & 3,05 & 3,51 & \\
\hline 7 & Pegar as peças dos contêineres 1 e 2 & 5 & 3 & 3,45 & \\
\hline 8 & Levar e soltar as peças nas rampas 3 e 4 & 5 & 3,25 & 3,74 & \\
\hline 9 & Retornar as mãos aos contêineres 1 e 2 & 4 & 2,44 & 2,81 & \\
\hline 10 & Queda das peças nas rampas até o depósito & 1 & 0,79 & 0,91 & \\
\hline \multicolumn{2}{|c|}{ Total } & 52 & 32,38 & 37,25 & 33,51 \\
\hline
\end{tabular}

\section{Legenda:}

$\mathrm{R}$ : repetições

TN (s): tempo normal (s)

TP (s): tempo padrão (s)

TNT (s): tempo normal total (s)

Fonte: Autoria Própria (2019)

A tabela 1 está constituída das informações cronometradas na execução do jogo descrito no artigo, onde:

- O tempo normal foi calculado da seguinte forma:

$\mathrm{TN}($ tempo normal $)=\mathrm{TC}($ tempo cronometrado da atividade $) \mathrm{x} \mathrm{V}$ (velocidade $) \mathrm{x}$.

- O tempo padrão foi calculado da seguinte forma:

TP $($ tempo padrão $)=$ TN (tempo normal) $\mathrm{x}$ FT (Fator de tolerância).

- O tempo normal total (TNT) é a cronometragem contínua ao decorrer da contagem do tempo da execução do jogo.

Nesse caso, a velocidade (V) foi considerada igual a 1 e o fator de tolerância (FT) igual a 1,15. Em adição, o tempo padrão (TP) é o tempo necessário para realizar uma operação de acordo com uma disciplina determinada, trabalhando em ritmo normal durante toda a realização do jogo. 
Percebe-se, destarte, que o TNT é aproximadamente igual à soma total do TN, o que deixa nítido que a execução da cronoanálise foi realizada com êxito.

\section{Considerações finais}

Após a realização do estudo, é possível perceber, portanto, que o objetivo do trabalho foi alcançado, uma vez que foi criado o jogo corporativo e aplicado a engenharia de métodos nele. Além disso, a utilização do produto é de grande aplicabilidade nas instituições de ensino, pois amplia a visão dos professores quanto às operações, facilitando a melhoria de processos. Esta pesquisa procurou estudar a literatura acessível sobre a engenharia de métodos em vários dados de pesquisa universitária, sob o cenário principal da verificação de tempos e movimentos com base no jogo abordado.

Algumas melhorias propostas no trabalho são de fácil aplicabilidade como as questões de melhoramento de processos ao ter mais agilidade na execução de determinada tarefa em menor tempo. Por fim, é válido salientar que o tratamento da problemática será um diferencial na procura da agilidade e aumento da capacidade em menos tempo e consequentemente no acréscimo da aprendizagem de ensino do aluno na área de engenharia de métodos, envolvendo tempo, método e movimento na melhor forma possível.

\section{REFERÊNCIAS}

ANIS, Gerson Castiglieri. A importância dos estudos de tempos e métodos para controle da produtividade e qualidade. Setembro de, 2010.

AZEVEDO, thayane. Engenharia de produção. A importância da engenharia de métodos. Disponível em < https://eproducao.eng.br/a-importancia-da-engenharia-de-metodos/>. Acesso em: 02 dez.2019.

BARNES, Ralph M. Estudo de movimentos e de tempos: projeto e medida do trabalho. Editora Blucher, 1977.

DA CIVILIZAÇÃO, OS JOGOS NA HISTÓRIA. O MOVIMENTO E OS JOGOS.

LACRUZ, Adonai José. Jogos de empresas: considerações teóricas. Caderno de pesquisas em administração, v. 11, n. 4, p. 93-109, 2004.

NEVES, Rosane; ANJOS, Pamela. Oficinas de jogos de empresa. 2014. 
OLIVEIRA, Cassia Luciana Pfister Alves. Análise e controle da produção em empresa têxtil, através da cronoanálise. 2009.

REGINA,katia. Twygo. Jogos corporativos: o que são e como aplicar. Disponível em< https://www.twygoead.com/site/blog/jogos-corporativos >. Acesso em: 02 dez.2019.

SHIMIZU, Tamio. Decisões nas organizações: introdução aos problemas de decisão encontrados nas organizações e nos sistemas de apoio à decisão. Atlas, 2001. 